\title{
PROFISSIONALISMO E SECRETARIADO: HISTÓRIA DA CONSOLIDAÇÃO DA PROFISSÃO
}

\section{PROFESSIONALISM AND SECRETARIAL PROFESSION: HISTORY OF THE PROFESSION CONSOLIDATION}

Rosana Maria César Del Picchia de Araujo Nogueira

Doutora em Educação e Ciências Sociais pela Pontifícia Universidade Católica de São Paulo PUC/SP

Pesquisadora da Escola de Comunicação e Artes da Universidade de São Paulo - ECA/USP e da Pontifícia Universidade Católica de São Paulo - PUC/SP

E-mail: rosananog@uol.com.br (Brasil)

\section{Joyce de Souza Ferreira de Oliveira}

Estudante de Tecnologia em Secretariado da Faculdade de Tecnologia de Carapicuiba - Fatec E-mail: joycefoliveira@gmail.com (Brasil) 


\title{
PROFISSIONALISMO E SECRETARIADO: HISTÓRIA DA CONSOLIDAÇÃO DA PROFISSÃO
}

\begin{abstract}
RESUMO
Ao longo de sua história no Brasil, a profissão de secretariado tem buscado reconhecimento e valorização no mercado de trabalho pela arregimentação de seus pares e dessa forma obtido diversas conquistas. Com o objetivo de ampliar a compreensão do processo de consolidação do secretariado como profissão no Brasil, o presente artigo realiza dois movimentos de revisão. Tratase, no primeiro, dos mecanismos que a sociologia das profissões tem apontado como legitimadores das práticas ocupacionais. Aborda-se, em seguida, a história do secretariado no Brasil, com foco nas conquistas alcançadas pelos movimentos da categoria em busca da legitimação da profissão e da reserva de mercado de trabalho para os legitimados. A partir da revisão bibliográfica, estabelecemse comparações entre as etapas de consolidação consideradas típicas pela sociologia das profissões e as etapas já vivenciadas pela profissão do secretariado no Brasil. Conclui-se que, conquanto o secretariado tenha passado pelas mesmas etapas de consolidação de profissões já tradicionalmente estabelecidas no mercado brasileiro, a inexistência de um órgão regulador e disciplinador, em forma de conselho, dificulta a garantia de mercado exclusivo aos profissionais já credenciados.
\end{abstract}

Palavras-chave: Profissionalismo; História do Secretariado; Conselho Profissional.

\section{PROFESSIONALISM AND SECRETARIAL PROFESSION: HISTORY OF THE PROFESSION CONSOLIDATION}

\begin{abstract}
Throughout its history in Brazil, the secretarial profession has sought recognition and recovery in the labor market by the regimentation of their peers and thereby obtained many achievements. With the purpose of broaden the understanding of secretarial profession consolidation process in Brazil, the present article performs two movements review. The first is about the mechanisms that the Sociology of Professions has pointed as legitimate of the occupational practices. Then it approaches the history of the secretarial profession in Brazil, focusing on the accomplishments achieved by the category profession mobilization in search of the profession legitimacy and the labor market reserve for the legitimized. From the literature review, set up comparisons between consolidation phases considered typical for the sociology of professions and the steps that Secretarial Profession already experienced in Brazil. It concludes that, although the secretarial profession has passed through the same consolidation stages of professions traditionally established in the Brazilian market, the absence of a regulator and disciplinarian body, as a council, makes difficult guaranteeing exclusive market for the already accredited professionals.
\end{abstract}

Keywords: Professionalism. The history of Secretarial Profession. Professional Association. 


\section{INTRODUÇÃO}

Entende-se por profissionalismo o processo social desenvolvido pelos praticantes de uma ocupação em busca de legitimidade frente à sociedade para exercer certa exclusividade sobre as práticas ocupacionais que desenvolvem (Nascimento, 2007). Nesse processo, as organizações profissionais necessitam de relações com outras esferas da vida social, como instituições educacionais e o próprio Estado.

De acordo com Freidson (1996), as profissões se estabelecem por elementos como o monopólio sobre determinada área do conhecimento, o credenciamento por meio de diplomação em ensino superior e a reserva de mercado de trabalho, valendo-se de mecanismos de credenciamento.

Entendendo que legitimação e credenciamento sejam de interesse primeiro dos praticantes de certa ocupação, apontam-se, de forma geral, os movimentos profissionais como impulsionadores dos mecanismos de profissionalização. No entanto, especialmente para a realidade brasileira, Marinho (1986) destaca o forte impacto da intervenção estatal nos processos de profissionalização. Ele destaca, principalmente, o fato de que às associações de classe e aos sindicatos não é permitido assumirem toda a ação reguladora e disciplinadora sobre a profissão que representam, dependendo da criação de conselhos profissionais, ligados ao Governo Federal, para esse fim.

Ao se analisar a trajetória do secretariado no Brasil, observa-se uma profissão que venceu muitos desafios, participou de mudanças importantes no cenário organizacional mundial e se adaptou às constantes inovações de tecnologia e de mercado (Castelo, 2007).

Do simples servente dos anos de 1950, passando por símbolo de status gerencial na década de 1960, o profissional de secretariado encontrou nos anos de 1970 o momento propício para início da valorização da profissão: as teorias gerenciais que emergiram valorizaram o papel do secretário, o surgimento de cursos superiores e de treinamentos permitiram a percepção do papel que representavam nas instituições e começam a surgir as associações de classe. Essas associações veem seus movimentos fortalecidos na década de 1980, com a criação dos sindicatos estaduais, o surgimento da Fenassec - Federação Nacional de Secretárias e Secretários, a elaboração e adoção do Código de Ética e com a regulamentação da profissão (Sála, 2008).

Foi por meio de lutas e ações em prol do respeito e reconhecimento da profissão que as conquistas puderam ser alcançadas. A profissão foi regulamentada em 30/9/1985 pela Lei n. 7.377/85 e essa complementada pela Lei n. 9.261/96, que representaram uma vitória incomparável para secretários e secretárias (Castelo, 2007).

Revista de Gestão e Secretariado - GeSec, São Paulo, v. 4, n. 2, p 01-24, jul./dez. 2013. 
Iniciou-se no ano de 1996 a luta pela criação de um Conselho Federal do Secretariado, por meio de ações junto a parlamentares por iniciativa de diversos sindicatos filiados à Fenassec. Buscando autorização para criar uma entidade que, ao fiscalizar o exercício profissional do secretariado, impulsionasse o aumento do número de vagas no mercado e a própria valorização da profissão, mas tal movimento esbarrou em empecilhos que mantêm o assunto em tramitação até a atualidade (Ferreira, 2011).

Se as mudanças ocorridas no mercado de trabalho brasileiro exigiram uma nova visão gerencial que permitia a administração participativa, o profissional de secretariado atualizou-se para elas, chegando à década de 1990 com perfil empreendedor, capaz de agir como gestor e oferecer consultoria, assumindo função de assessoria (Sála, 2008).

Contudo, os movimentos de classe ainda lutam para que todas as conquistas da profissão, garantidas por lei, sejam cumpridas pelo mercado de trabalho. Neste artigo, busca-se responder, pela revisão dos conceitos de profissionalismo e da história do secretariado no Brasil, se a criação de um Conselho Federal para o secretariado, regulador e disciplinador da profissão, atenderia à necessidade da categoria de uma fiscalização do exercício profissional que proporcionaria a própria valorização da profissão.

\section{MECANISMOS DO PROFISSIONALISMO}

Uma profissão é uma prática social, dependente em sua gênese e continuidade de fatores ligados à história da humanidade e das modificações que ela traz às formas de se organizar e se dividir o trabalho, como bem apontou Sousa Neto (2005) em seu ensaio acerca do lugar social da profissão docente.

\footnotetext{
Não por acaso é que muitas profissões já existiram e desapareceram completamente condutores de bonde puxados a burro, linotipistas, turmeiros. Outras tantas estão prestes a desaparecer - trocadores de ônibus, frentistas, datilógrafos. E várias são aquelas que terão de se adaptar a novos parâmetros técnicos e demandas sociais. Daí podermos dizer que as profissões se mantêm e se modificam, desaparecem ou passam a existir mediante as necessidades reais ou imaginárias que as sociedades historicamente datadas têm ou criam (Neto, 2005, pp. 253-254) (grifos do autor).
}

O lugar social das profissões, nesse sentido, está diretamente ligado à história da humanidade e às metamorfoses no mundo do trabalho, proporcionadas pela própria complexidade da sua divisão social.

Revista de Gestão e Secretariado - GeSec, São Paulo, v. 4, n. 2, p 01-24, jul./dez. 2013. 
Foi a partir das intensas mudanças sociais e econômicas ocorridas globalmente nas décadas de 1970 e de 1980 que a sociologia das profissões ganhou força, já que tais mudanças implicariam novas formas de organização do mercado de trabalho. Esse período de incertezas levava a questões sobre como evoluiriam as profissões: se para um fortalecimento de seus monopólios e direitos ou para o declínio de poder e controle profissionais (Kober, 2003).

Voltando o olhar para a história das profissões no Brasil nos séculos XX e XXI, destacam-se alguns períodos de grandes mudanças e reorganizações. Marinho (1986) apontou que o processo de industrialização brasileiro, iniciado com a Revolução de 1930 e complementado pelos esforços das políticas estatais de desenvolvimento, como as do Governo de Juscelino Kubitschek, na década de 1950, foi o propulsor da diversificação do mercado de trabalho no país.

Transformações maiores viriam com a redemocratização do Estado, que apresentou a promulgação da Constituição de 1988 como seu maior ícone e que possibilitou a década de reformas de 1990 (Faria \& Leão, 2007).

Segundo Faria e Leão (2007, p. 2)

Neste período de transposição do século XX para o XXI, o capitalismo adota uma alternativa de flexibilização, há uma grande preocupação dos envolvidos em preparar os trabalhadores para que estes estejam adequados às necessidades do capital, que se informatiza, se tecnifica e também conduz a precarização, fragmentação e terceirização do trabalho.

A liberalização comercial do início da década de 1990, realizada de forma rápida e abrangente, trouxe impacto em quase todos os setores econômicos do país, gerando como consequências o aumento da taxa de desemprego, da informalidade e da produtividade do trabalho (Soares, Servo \& Arbache, 2001).

Para o início dos anos 2000, algumas medidas do governo federal ampliam as características flexíveis das relações de trabalho no país, mas outras mantêm e promovem direitos trabalhistas como salário mínimo, licença-maternidade e abrangência da fiscalização. Identifica-se, portanto, um momento de incertezas sobre as profissões no Brasil em que Krein (2007) ressaltou como a grande polêmica se o país caminhará para a "reafirmação de um sistema de regulação pública do trabalho ou avanço rumo à flexibilização das relações de trabalho" (p. 103).

Destaca-se, assim, que o momento vivido atualmente no Brasil, do ponto de vista das formas de organização e divisão do trabalho, é propício para uma reflexão com base na sociologia das profissões. 
O olhar sociológico sobre as profissões tem se pautado, conforme apontou Marinho (1986), em duas vertentes diferentes: uma que tenta conceituar o que é profissão e outra que se ocupa com as discussões a respeito dos processos ou mecanismos de profissionalização. É da segunda vertente o artigo de Freidson (1996) usado como base para a revisão e análise a que se dedicou este trabalho.

Ao escolher abordar o Secretariado Executivo como uma profissão em processo de consolidação, este artigo se valeu dos conceitos da sociologia das profissões, especialmente pelos utilizados por Freidson (1996) na busca de criar o que pretendia ser um tipo ideal de profissionalismo, analisando "os órgãos e os recursos exigidos para que ele se estabeleça" (Freidson, 1996, p. 2). Podem-se definir, a partir desse conceito, alguns passos ou etapas que as ocupações trilham até chegarem a sua consolidação como profissão.

Nas subseções a seguir, procura-se definir três das etapas da profissionalização: o monopólio sobre uma área especializada do conhecimento, a obtenção de credenciais no ensino superior e a autonomia profissional para realizar diagnósticos e controlar o mercado, estando essa última relacionada com a forma como o Estado intervém sobre a divisão e organização do trabalho.

\subsection{MONOPÓLIO SOBRE UMA ÁREA ESPECIALIZADA DO CONHECIMENTO}

O profissionalismo foi apontado por Freidson (1996) como uma forma distinta de se organizar a divisão do trabalho em sociedade. Enquanto o método de divisão do trabalho baseado no livre-mercado colocaria nas mãos dos consumidores o controle de selecionar e organizar os trabalhadores e o método burocrático creditaria a uma administração centralizada esse controle, na lógica da organização de trabalho pelo profissionalismo são as próprias ocupações que "negociam limites jurisdicionais entre si, estabelecem e controlam sua própria divisão do trabalho" (Freidson, 1996, p. 2). A primeira etapa para que uma ocupação possa assumir esse poder de negociação sobre a divisão do trabalho é que seja reconhecida socialmente como uma especialização, como um tipo específico de trabalho especializado.

Ao se definir profissão, duas características iniciais são ressaltadas. Primeiro, o trabalho que é realizado em tempo integral e o segundo, o qual é recompensado formalmente. No entanto, há muitos tipos de trabalho que mesmo sendo realizados em tempo integral e sendo remunerados, não são reconhecidos oficialmente. Reconhecimento oficial, portanto, pode ser afirmado como essencial característica do conceito de profissão (Freidson, 1996). Como muitas profissões se originaram de ocupações não oficiais que eram realizadas no mercado informal, torna-se importante indagar que aspectos diferenciam o processo daquelas que se consolidaram oficialmente das que não se

Revista de Gestão e Secretariado - GeSec, São Paulo, v. 4, n. 2, p 01-24, jul./dez. 2013. 
efetivaram como profissão.

Nesse processo, tem se destacado o aspecto da especialização que se relaciona aos tipos de conhecimentos e habilidades considerados necessários para a prática de determinada atividade profissional.

Neste sentido, Nascimento (2007) afirmou que:

[...] o agir profissional está ligado à ideia de que os indivíduos que assim atuam no mercado de trabalho possuem um conhecimento específico - conhecimento especializado em uma área, como Direito Tributário, Mercado Financeiro - e o utilizam em suas atividades, em seu trabalho (Nascimento, 2007, p.106).

Entende-se que a posse de tais conhecimentos específicos possibilitaria um monopólio sobre determinada atividade profissional por classificar automaticamente aos que não os possuem como leigos e, portanto, carentes de orientação no assunto.

Importa citar o esclarecimento que Freidson (1996) faz acerca da ideia de atividade especializada estar presente em quase qualquer trabalho que se realize em uma sociedade industrial, por terem como exigência mínima treinamento e prática. Para o autor, o distanciamento entre as atividades laborais que exigem menor qualificação e as profissões (consideradas pelo autor como ocupações altamente qualificadas) se dá pelo grau em que essas atividades são simples e repetitivas ou exigem discernimento e julgamento a cada circunstância.

$\mathrm{O}$ autor classifica o trabalho das profissões como "uma especialização criteriosa teoricamente fundamentada" (Freidson, 1996, p. 2), em que: criteriosa, indica a atividade que por sua variedade de contingências exige um trabalhador com discernimento para adaptar seus conhecimentos e habilidades a cada circunstância; e, teoricamente fundamentada, descreve o trabalho que exige formação com base em conceitos e teorias abstratas e não apenas em longos treinamentos práticos.

Caracterizada dessa forma, a profissão exigiria um preparo além do que pode ser oferecido no próprio ambiente de trabalho. Passa a necessitar, muitas vezes, do preparo em nível superior que acaba por se caracterizar como uma forma de controle do exercício de uma profissão, já que para participar de uma comunidade profissional são exigidas credenciais que comprovem o domínio de conhecimentos e habilidades próprios àquele trabalho.

\subsection{OBTENÇÃO DE CREDENCIAIS NO ENSINO SUPERIOR}

Revista de Gestão e Secretariado - GeSec, São Paulo, v. 4, n. 2, p 01-24, jul./dez. 2013. 
Para entender o que Freidson (1996) conceituou por profissionalismo, é necessário citar a distinção que ele faz entre ofício e profissão. Ambas são atividades especializadas e criteriosas, mas diferem em sua fundamentação que, no ofício, está mais voltada para a prática, e na profissão voltase para a teoria e o conhecimento abstrato. É por essa razão que o autor afirmou que o treinamento vocacional para um ofício ocorre dentro do mercado de trabalho, preferencialmente, nas mesmas instalações em que trabalhem os já credenciados para aquela atividade. Por outro lado, o treinamento para uma profissão se dá fora do mercado de trabalho, em instituições de ensino. Portanto, o autor entendeu profissão por aquele trabalho que exige diploma de nível superior.

Ao explicar as diferenças entre esses dois modelos de treinamento vocacional, Freidson (1996, p. 3) comprovou que "O treinamento vocacional é de fato a chave tanto para o controle ocupacional do próprio lugar em uma divisão do trabalho, como do próprio status no mercado de trabalho".

Para as ocupações, o treinamento vocacional realizado dentro do ambiente de trabalho, tendo como professores os próprios membros de determinada ocupação que se dedicam ao ensino como atividade complementar, criou a cultura de controle do trabalho pelo segredo, em que o conhecimento especializado é dividido apenas com quem é admitido no aprendizado, e também pela prática de greves e manifestações.

Já para as profissões, o treinamento vocacional realizado fora do ambiente de trabalho, em que o ensino é uma atividade de tempo integral, possibilitou a formação de um corpo acadêmico da área profissional que, em suas atividades de pesquisa e estudo, atua positivamente na "capacidade de uma profissão para justificar, adaptar e expandir sua jurisdição diante da competição de outras ocupações, bem como da crescente sofisticação da população leiga e dos avanços tecnológicos e administrativos na racionalização" (Freidson, 1996, p. 3).

O credenciamento por diplomação em nível superior é considerado etapa do profissionalismo de uma ocupação por controlar o acesso à prática daquela atividade e por oferecer base teórica a favor do status de uma profissão dentro do mercado de trabalho, por meio da influência do conhecimento acadêmico (Freidson, 1996).

\subsection{AUTONOMIA PROFISSIONAL PARA REALIZAR DIAGNÓSTICOS E CONTROLAR O MERCADO - A INTERVENÇÃO DO ESTADO}

Revista de Gestão e Secretariado - GeSec, São Paulo, v. 4, n. 2, p 01-24, jul./dez. 2013. 
Considerando uma sociedade em que as tarefas têm sido grandemente divididas e especializadas, as condições para continuidade de uma atividade permeiam sua capacidade de se relacionar funcionalmente com outras atividades. Para que vários grupos não se sobreponham sobre a mesma atividade, tende-se a criar mecanismos que garantam certa segurança de que aquele espaço na divisão do trabalho continue existindo e de que outros grupos não venham a ocupá-lo (Freidson, 1996).

Aplicam-se mecanismos para que haja uma reserva de mercado de trabalho que, segundo Freidson (1996, p. 3), “é assegurada pela exigência de que somente aqueles com credencial ocupacionalmente emitida, certificando sua competência, possam ser empregados para executar uma série definida de tarefas".

Para obter reserva no mercado de trabalho, as profissões se valem de diversos mecanismos: legislação de reconhecimento e regulamentação profissional, credenciamento em ensino superior, regulação por órgãos de classe profissional. A existência e utilização de qualquer um desses mecanismos dependem de como o Estado se posicionará acerca do papel que as profissões ou grupos profissionais exercerão sobre o controle do mercado de trabalho. É por isso que Freidson destacou o Estado como a variável mais importante para o profissionalismo.

$\mathrm{O}$ autor ainda afirmou que:

O único recurso intrínseco a uma ocupação é seu corpo de conhecimentos e qualificações, e, embora este possa ser chamado de capital humano e cultural, certamente não tem o poder do capital econômico ou político. As instituições do profissionalismo não podem ser estabelecidas ou mantidas sem o exercício do poder do Estado, pois o controle ocupacional da própria divisão do trabalho, do próprio mercado de trabalho e do modo de ensino vai contra o interesse tanto dos consumidores individuais como das empresas (Freidson, 1996, p. 6).

Em sua análise, o autor passou a definir quatro formas entre as quais os Estados podem organizar e controlar o trabalho, tendo por base a tipologia defendida por Mirjan Damaska (1986, como citado em Freidson, 1996).

Em um formato de Estado coordenativo-reativo, de característica passiva, as associações profissionais se auto-organizam e assumem funções como negociar a divisão do trabalho com outras ocupações, estabelecer escolas, criar credenciais, sendo responsáveis por criar reservas no mercado de trabalho. Aos órgãos do Estado ficariam restringidas as atividades de resolução de

Revista de Gestão e Secretariado - GeSec, São Paulo, v. 4, n. 2, p 01-24, jul./dez. 2013. 
questões que não puderam ser resolvidas privadamente bem como implantação de medidas de divisão do trabalho e treinamento ocupacional que já tenham tido sua conveniência atestada.

Para Estados hierárquico-reativos, em que se combinam a organização hierarquizada de órgãos estatais com a participação da sociedade civil por meio de grupos organizados ou de forma individual, as funções de formular e administrar as divisões e reservas de trabalho e estabelecer programas de treinamento vocacional, provavelmente ficariam a cargo de um órgão estatal. Tal órgão poderia possibilitar a participação da sociedade civil ao basear sua atuação em recomendações de associações profissionais independentes, mas poderia também assumir essas funções por meio de seu pessoal profissionalmente qualificado que atuaria em nome de uma profissão, sem seguir a vontade expressa das associações.

No segundo caso, poderiam ser consultados representantes de associações profissionais ou convidar membros destacados da profissão ou uma associação para representar a profissão como um todo nas negociações.

Para o caso de um Estado se organizar de maneira hierárquica-ativista, em que qualquer grupo civil que mantenha visão diferente da defendida pelo Estado é desencorajado ou suprimido, a existência de uma associação profissional só seria possível se criada pelo próprio Estado e qualquer atuação na divisão e reserva do mercado de trabalho seria dominada por ela.

Caso um Estado assumisse posição coordenativa-ativista, descentralizadora e de forte participação civil, possivelmente não apoiaria o estabelecimento do profissionalismo por se mostrar contrário a ideia de um status privilegiado aos tecnicamente qualificados.

Exceto pelo último tipo apresentado, em qualquer forma de organização seria possível a existência do profissionalismo. E aqui Freidson (1996) se diferenciou de outros autores sobre a essencialidade da presença de associações profissionais para que o profissionalismo venha a se estabelecer.

Para Freidson (1996), o Estado pode agir a favor do status de um grupo de profissionais sem que uma associação de classe venha a existir. Ele ressalta que uma associação se compõe de um conjunto de profissionais que por sua diferenciação em especialização, autoridade cognitiva e administrativa, raramente atingirá um consenso, exceto em questões mais gerais. Havendo diversas posições sobre um assunto dentro de uma associação profissional, o Estado poderia apoiar as que fossem compatíveis com suas políticas, o que não se diferenciaria muito do fato de que, na inexistência de associações profissionais, membros de uma profissão com maior status político e intelectual poderiam influenciar em decisões estatais sobre questões relacionadas à sua profissão.

Em posição contrária, o estudo realizado por Marinho (1986) tomou por base o exposto por

Revista de Gestão e Secretariado - GeSec, São Paulo, v. 4, n. 2, p 01-24, jul./dez. 2013. 
Wilensky (1970, como citado em Marinho, 1986, p. 31), em que a criação de uma associação profissional é considerada a segunda das cinco etapas do processo de profissionalização típico, por ser "importante passo para a definição e construção da identidade profissional e redução da identificação com as ocupações previamente existentes e pouco profissionalizantes". As outras quatro etapas por ele consideradas são: o trabalho tornar-se ocupação de tempo integral, criação de escolas para treinamento, regulamentação da profissão e adoção de um código de ética.

Em sua análise, Marinho (1986) deu especial ênfase ao papel da intervenção do Estado sobre o mercado profissional que, no caso brasileiro, considerava muito forte. No país, a representação profissional se faz por meio de um tripé formado por sindicatos, associações e conselhos. Em contraste a esse formato, o autor apresentou o exemplo dos Estados Unidos, em que as associações profissionais assumem as principais responsabilidades sobre o controle profissional: determinam os requisitos necessários à prática profissional, atestando os qualificados e rejeitando os não qualificados, influenciando inclusive a área educacional, em relação aos currículos praticados pelos cursos de formação.

No Brasil, os sindicatos assumem a representação de uma categoria ou profissão liberal perante autoridades administrativas e judiciárias, sendo exemplos de suas responsabilidades a celebração de contratos coletivos de trabalho e o promover a conciliação nos casos de dissídio (Decreto-lei n. 5.452, 1943).

Quanto à associação profissional de caráter não sindical, seria sua atuação limitada a atividades que objetivem o estudo e a defesa de interesses econômicos e profissionais de seus afiliados (Silva, 2005). Ainda que não possuam prerrogativas legais para exercer poder de punição, nem representar profissionais em disputas trabalhistas, as associações profissionais são consideradas grupos que exercem pressão na decisão de questões relativas à profissão.

A forma de representação capaz de fiscalizar o exercício profissional e formular resoluções complementares à legislação em vigência é o Conselho Profissional, instituído unicamente por lei federal. Com responsabilidades que se atribuiriam ao Estado segundo o disposto nos artigos $5^{\circ}$, XIII, 21, XXIV, e 22, XVI da Constituição Federal, os Conselhos Profissionais são autarquias do poder estatal, ainda que possuam autonomia administrativa e financeira (Costa, 2009).

Ressalta-se assim que, na sociedade brasileira, a intervenção estatal sobre o controle profissional é simbolizada pelo fato de que as únicas formas de representação com autonomia para regular e fiscalizar o exercício de uma profissão, quais sejam, o Conselho Federal e os Conselhos

Regionais a ele ligados, dependem de lei federal para vir a existir.

Revista de Gestão e Secretariado - GeSec, São Paulo, v. 4, n. 2, p 01-24, jul./dez. 2013. 
Ainda se observa que para exercer uma profissão regulamentada seja necessário ao interessado possuir diploma registrado no Ministério da Educação e, pela posse deste, obter seu registro profissional no Ministério do Trabalho. Em caso de não haver para sua profissão Conselho Regional pertinente, já se encontrará apto a exercê-la, sendo facultativa a inscrição em sindicato ou associação profissional. (Marinho, 1986). Dessa forma, um novo profissional chegaria ao mercado de trabalho sem que houvesse qualquer atuação de seus pares sobre sua formação e sua forma de exercer a profissão, recaindo sobre o processo apenas o controle estatal.

\section{HISTÓRIA DO SECRETARIADO NO BRASIL}

A origem da profissão de secretariado tem sido apontada no trabalho que os escribas realizavam na Antiguidade, em fazer cálculos, arquivar registros, redigir e ler documentos, e ser sigilosos sobre os dados a que tinham acesso. Exercida por pessoas do sexo masculino, a função gozava de prestígio pela detenção de conhecimento que se tornava importante à administração pública, redundando em privilégios e poder aos escribas (Castelo, 2007).

É a partir da Revolução Industrial, com o ressurgimento do comércio, que a profissão de Secretário Executivo se consolidará. Pela escassez de mão de obra masculina direcionada aos campos de batalha durante as Guerras Mundiais, a atuação na área ganhou predominância feminina, especialmente nos Estados Unidos e na Europa (Ferreira, 2011).

Dessa forma, quando na década de 1950 as empresas multinacionais chegam ao Brasil, já tinham incorporada a presença da mulher como secretária em sua cultura organizacional (Natalense, 1998). O papel dessa profissional nas empresas era limitado à execução de atividades da rotina secretarial, atendendo ao telefone, datilografando e arquivando documentos, anotando recados.

Durante a década de 1960, em que as empresas iniciam treinamentos importados dos Estados Unidos de formação de gerentes, ter uma secretária passou a representar um dos fatores do status gerencial, ao lado de outros fatores como ter uma sala confortável ou um motorista. Essa visão ultrapassou o ambiente corporativo e o termo secretária passou a representar diversos profissionais, sendo que até mesmo as empregadas domésticas receberam a alcunha de "secretárias do lar”, causando desvalorização à verdadeira profisssão, como afirmou Sála (2008, p. 6).

Sála (2008) apontou a década de 1970 como a de princípios da mudança, em que o treinamento para secretárias e a possibilidade de formação superior, bem como a divulgação de teorias da administração que as valorizavam, permitiram a essas profissionais entender seu

Revista de Gestão e Secretariado - GeSec, São Paulo, v. 4, n. 2, p 01-24, jul./dez. 2013. 
verdadeiro papel. Também é registrado o surgimento das associações de classe que se fortaleceram na luta por regulamentação da profissão, efetivada na década seguinte.

Nos anos de 1980, com os avanços tecnológicos e com os conhecimentos gerenciais pautados em administração participativa, reengenharia e qualidade sendo grandemente difundidos nas empresas, o profissional de secretariado passou a ser considerado parte de uma equipe em conjunto com seu gerente, deixando para trás a posição de simples servente (Natalense, 1998). Estão registradas nessa década as grandes conquistas da categoria, como a regulamentação da profissão, a criação da Federação Nacional de Secretárias e Secretários - Fenassec - e a adoção do Código de Ética Profissional.

Já a década de 1990 é marcada pela crescente complexidade da atuação do profissional de secretariado com as técnicas secretariais deixando de representar o aspecto central de seu trabalho e o perfil empreendedor, polivalente, gerador de lucros e resultados sendo cada vez mais requisitado. Os profissionais adquiriram consciência de que sua atuação individual poderia impactar a consolidação e reconhecimento da profissão e passaram a procurar aperfeiçoamento por meio de treinamentos e cursos superiores para melhorar sua eficiência na função (Castelo, 2007).

Dessa forma, o profissional de secretariado inicia o século XXI como autogestor de sua carreira, sabendo que em um mundo de constante mudança o conhecimento necessário ao exercício de sua profissão será fruto de aprendizado contínuo, não se limitando ao adquirido academicamente. Esse profissional adquiriu visão global dos negócios, pronto não apenas para se ajustar às mudanças, mas sendo capaz de liderar processos de mudanças dentro da organização. Ele também procurou manter domínio tanto das técnicas secretariais tradicionais, quanto sobre as novas tecnologias que apoiam seu trabalho. Estendeu suas competências para além dos conhecimentos e habilidades requeridos, desenvolvendo atitudes como iniciativa, participação e inovação, que o transformaram em gestor de informação, da comunicação e dos conflitos da empresa. Além disso, conseguiu alinhar sua atuação aos objetivos da empresa, prestando assessoria pró-ativa ao entregar aos executivos informações necessárias ao gerenciamento das decisões (Sála, 2008).

O patamar alcançado pela profissão exigiu, por décadas, lutas e ações empenhadas por profissionais do Secretariado, representantes de associações e sindicatos, coordenadores, professores e alunos dos cursos de graduação em Secretariado, em busca de consolidação e reconhecimento.

Pode-se encontrar um exemplo característico do profissionalismo nas lutas e conquistas da 
profissão de secretariado, em que os praticantes de uma ocupação buscam, em diversas esferas da vida social, mecanismos que lhes garantam espaço no mercado de trabalho.

\subsection{HISTÓRICO DE LUTAS E CONQUISTAS DO SECRETARIADO}

Para a pesquisa sobre a trajetória das lutas e conquistas de secretários e secretárias por sua profissão, a presente seção utiliza como referencial o que abordou Castelo (2007) ao estudar sobre a formação acadêmica e atuação do Secretário Executivo, como também o que Ferreira (2011) realizou em seu trabalho sobre a atuação desse profissional no setor público. Consulta ainda os pontos destacados por Bruno (2006) acerca do processo da organização profissional do Brasil ao dissertar sobre o poder de influência do profissional de Secretariado.

Data da década de 1960 o surgimento da primeira organização de classe do Secretariado. O Clube das Secretárias do Rio de Janeiro foi fundado em 16/12/1965 e reconhecido como utilidade pública em 3/12/1968 pela Lei 1.784 da Assembleia Legislativa do Estado da Guanabara. Incentivava o aprimoramento cultural das associadas, o intercâmbio de conhecimentos, a prática e a difusão de elevadas normas da ética profissional por meio das boas relações sociais, companheirismo e convivência entre suas sócias.

Em 15/12/1970 o Clube das Secretárias tornou-se a Associação das Secretárias Executivas do Rio de Janeiro - ASSERJ, representando o avanço dos movimentos isolados que se transformavam em associações civis. Primeira associação civil que pretendia reunir a classe, que tinha entre seus objetivos cultivar e estabelecer relações com as secretárias que exerciam suas atividades no estado do Rio de Janeiro; zelar pela união, promovendo os meios necessários para congregá-las em reuniões culturais, sociais e de trabalho; estabelecer o intercâmbio com associações similares ou que se propunham ao mesmo fim; e promover a valorização e defesa da profissão.

Em nome desses objetivos, a ASSERJ realizou dois eventos marcantes para a categoria. Em 1977, o I Encontro de Secretárias do Rio de Janeiro e, em 1978, o I Congresso Nacional de Secretárias Executivas.

Para representar e coordenar as associações dos diversos estados brasileiros em nível nacional, foi criada a Associação Brasileira de Entidades de Secretárias - Abes, em 7/9/1976. A Abes passa a promover anualmente vários encontros nacionais e a apoiar as entidades regionais na realização de eventos regionalizados. Sua principal realização eram os bianuais Congressos Nacionais de Secretariado - CONSECs - que se constituíam em espaços para discussão da situação,

Revista de Gestão e Secretariado - GeSec, São Paulo, v. 4, n. 2, p 01-24, jul./dez. 2013. 
dos objetivos e das reivindicações da classe. A Lei 6.556/78, de 5/9/1978 originou-se das discussões realizadas nesses Congressos.

A referida Lei dispunha sobre a atividade de Secretário e vem a ser o reconhecimento formal da profissão. Para exercício da profissão, a lei exigia formação em curso de Secretariado em nível de segundo grau e registro na Delegacia Regional do Trabalho. Por não oferecer regulamentação da profissão que indicasse mecanismos de obrigatoriedade em seu cumprimento, não atendia completamente aos interesses da categoria.

Já a Lei n. 7.377, de 30/9/1985 que estabeleceu as diferenciações de formação e atribuições entre Secretário Executivo e Técnico em Secretariado se configurou como expressiva vitória da categoria por meio de sua Associação de representatividade nacional - a Abes. Por não amparar adequadamente os profissionais mais antigos em seu artigo $3^{\circ}$, foi considerada ineficiente.

É importante citar que um Código de Ética da Secretária Brasileira foi elaborado pela Abes, debatido e aprovado em Assembleia Geral no dia 30 de setembro de 1983, passando a ser adotado pela classe.

Foi pela aprovação da Portaria n. 3.103, de 29/4/1987, atribuindo ao secretariado enquadramento sindical em categoria profissional diferenciada dentro do plano da Confederação Nacional dos Trabalhadores no Comércio - CNTC - que passou a ser possível à categoria se organizar em sindicatos, cuja atuação era mais abrangente do que a das associações por possuírem amparo legal para representatividade dos profissionais, como conjunto, em questões jurídicas e administrativas.

A citada Portaria foi entregue às Presidentes de Associações reunidas em Brasília por ocasião do XI Encontro de Dirigentes de Entidades de Secretárias, promovido pela Abes. Nessa ocasião também foi entregue a Carta Sindical ao SISERGS - Sindicato das Secretárias e Secretários no Rio Grande do Sul - em 30/4/1987.

Nessa mesma época, a Associação do Distrito Federal obteve uma audiência com o Ministro do Trabalho, Almir Pazzianotto, para tratar da criação de seu sindicato e tomou a iniciativa de convidar representantes de entidades pares de outros estados para participarem da oportunidade. Com a resposta imediata de catorze associações estaduais mais o apoio do Sindicato de Secretárias do Rio Grande do Sul, o grupo passou a denominar-se Grupo Sindicalista Força 16. O Grupo, representado por oito de suas componentes, recebeu em 12 de novembro de 1987 a promessa formal de dar resposta favorável às solicitações do grupo para criação de seus sindicatos. 
O segundo estado a receber a Carta Sindical foi o Sindicato das Secretárias do Mato Grosso - Sisemat - em 24/12/1987. Em 4 de fevereiro de 1988, durante a abertura do I Encontro Interestadual de Sindicatos de Secretárias, os Estados de Santa Catarina, São Paulo, Bahia, Paraná, Minas Gerais, Rio de Janeiro, Pernambuco, Alagoas, Paraíba, Maranhão, Piauí e do Distrito Federal receberam suas Cartas Sindicais pelas mãos do então Ministro do Trabalho, Almir Pazzianotto.

No ano de 1988, durante o VI CONSEC - Congresso Nacional de Secretariado, em Curitiba, foi fundada a Fenassec - Federação Nacional das Secretárias e Secretários, com a presença de catorze Sindicatos Estaduais e duas Associações Profissionais. Os sindicatos de secretariado passam a ser representados por essa Federação que tem como objetivo principal atender aos interesses específicos da profissão.

Criado pelos sindicatos filiados à Fenassec, o Código de Ética do Profissional de Secretariado, mais abrangente do que o anterior, foi publicado no Diário Oficial da União de 7 de julho de 1989. O documento instituiu os princípios, direitos e deveres que devem ser seguidos por todos os secretários e secretárias, considerando que o comportamento ético traz contribuições à carreira individual e ao status que a profissão apresenta de forma geral.

Alguns anos mais tarde, em 1992, a categoria tem como importante documento de suas lutas a "Carta de Manaus", assim chamada por ter sido elaborada durante o VII Congresso Nacional de Secretariado, em Manaus. A Carta de Manaus sugeria alterações na Lei de Regulamentação da Profissão e apresentava outras questões como plano de carreira, piso salarial e currículo mínimo para cursos de formação na área.

Os anseios por alterações e complementações na regulamentação da profissão são correspondidos pela aprovação da Lei n. 9.261, de 10/01/1996 que enquadrou uma grande parte da categoria profissional, a qual não havia sido atendida pela legislação anterior.

Quanto aos cursos de graduação em Secretariado, o primeiro curso de formação foi criado em 1969, na Universidade da Bahia, e o primeiro curso a ser oficialmente reconhecido pelo Governo Federal, em 1978, foi o da Universidade Federal de Pernambuco (Castelo, 2007).

Presente desde a realização do I Encontro de Estudos Curriculares de Secretariado, em 1990, fazendo-se registrar na Carta de Manaus, de 1992, e impulsionando a primeira proposta com diretrizes curriculares para os cursos de secretariado executivo, encaminhada à Brasília em abril de 1999, a preocupação com a formação acadêmica do secretariado em nível superior se materializou em um documento elaborado durante o I Encontro Nacional de Coordenadores de Cursos de Secretariado Executivo. Nomeado Carta da Bahia, em referência ao estado que abrigou o evento, o documento continha deliberações para a formação do profissional de Secretariado Executivo que

Revista de Gestão e Secretariado - GeSec, São Paulo, v. 4, n. 2, p 01-24, jul./dez. 2013. 
foram encaminhadas à Secretaria de Ensino Superior - Sesu, do Ministério da Educação.

Finalmente, em 4 de abril de 2001 é publicado pelo Conselho Nacional de Educação o parecer n. CNE/CES 583/2001 fornecendo às Instituições de Ensino Superior as primeiras Diretrizes Curriculares para os cursos de graduação. O Parecer n. CNE/CES 102/2004 e sua Resolução de n. 3/05 concretizaram esse trabalho ao instituir as Diretrizes Curriculares Nacionais para o curso de graduação em Secretariado Executivo. As diretrizes curriculares reforçaram a necessidade de desenvolvimento de uma Teoria do Conhecimento em Secretariado, um dos desafios contemporâneos da profissão.

\subsection{HISTÓRICO DA CRIAÇÃO DE UM CONSELHO DO SECRETARIADO}

Outro importante desafio contemporâneo posto à profissão é efetivar a criação do Conselho Federal e dos Conselhos Regionais de Secretariado. O movimento pela criação desses Conselhos se iniciou em 1996 com a atuação da Fenassec e dos sindicatos junto a parlamentares em busca de apoio para aprovação da questão (Castelo, 2007).

Em 1998, o Projeto de Lei 91/98 foi apresentado ao Senado Federal pela senadora Regina Assunção. Mesmo tendo sido aprovado por diversas Comissões da Câmara e do Senado, recebeu veto da Presidência da República em maio de 2000 (Castelo, 2007).

$\mathrm{O}$ veto tem sido justificado pelo fato de o Projeto de Lei apresentar em seu texto a identificação da natureza jurídica do Conselho como pessoa jurídica de direito privado, o que a Lei n. 9.649/98, vigente na ocasião, permitia pela redação de seu artigo 58. No entanto, uma ação direta de inconstitucionalidade sobre o artigo referido - ADIN 1.717-6 - foi julgada procedente antes que o presidente sancionasse o Projeto de Lei que criaria o Conselho (www.fenassec.com.br, recuperado em 9, maio, 2013).

Os Conselhos Profissionais são considerados de natureza autárquica, por exercerem atividades típicas de Estado o que abrange até poder de polícia, de tributar e de punir, no que tange ao exercício de atividades profissionais, funções que só poderiam ser delegadas a entidades de caráter público. Tendo a prerrogativa de cobrar tributos, assumem o dever de prestar contas ao Tribunal de Contas da União (Costa, 2009).

A fixação do valor da contribuição devida aos Conselhos tem se tornado questão controversa entre várias posições jurídicas (Velloso, 2012). Aparece na mensagem de veto ao Projeto de Lei 91/98, menção a uma preocupação de que o Conselho Federal de Secretariado possa onerar

Revista de Gestão e Secretariado - GeSec, São Paulo, v. 4, n. 2, p 01-24, jul./dez. 2013. 
sobremaneira aos secretários ao instituir taxas e aplicar penalidades que não se justificariam do ponto de vista da proteção ao trabalho (Mensagem de Veto n. 663, 2000). Se configurado como pessoa jurídica de direito privado, o Conselho teria autonomia em sua contabilidade.

Um novo projeto foi encaminhado pela Fenassec ao Ministério do Trabalho em 26/02/2003, recebendo protocolo apenas em 7/10/2003. O projeto tem desde então tramitado entre Ministério do Trabalho e Casa Civil, sem significativo prosseguimento. A última posição registrada pela Fenassec em seu site, com data de 8 de junho de 2010, colocava o projeto em posse da Casa Civil e as esperanças se fixavam na aprovação de um Decreto que instituiria os critérios para a criação dos Conselhos Profissionais de profissões já regulamentadas que viria a facilitar a criação do Conselho de Secretariado (www.fenassec.com.br, recuperado em 9, maio, 2013).

A necessidade da criação dos Conselhos para fortalecimento da profissão foi apresentada por Castelo (2007).

\begin{abstract}
Com a criação dos Conselhos a FENASSEC e os Sindicatos de cada região poderão realizar de forma mais eficiente e positiva a Fiscalização e o Controle da Profissão, no que diz respeito principalmente ao cumprimento da Lei de Regulamentação orientando e conscientizando os empresários em exigir no processo de contratação dos profissionais de Secretariado o Registro Profissional, evitando assim, possíveis fraudes e a ocupação por esses profissionais de cargos com outras nomenclaturas. Poderão também emitir o Registro Profissional aos recém formados, agilizando tal processo e eliminando, consequentemente, a necessidade da solicitação de tal documento ser requerida junto ao Ministério do Trabalho (Castelo, 2007, p. 35).
\end{abstract}

As entidades de representação dos profissionais de secretariado tem expressado seu descontentamento em relação ao controle realizado pelo Ministério do Trabalho no credenciamento de profissionais e na fiscalização de possíveis fraudes. De outro lado, são impossibilitadas de atuarem nessas funções, se não pela existência de um Conselho Profissional que depende da aprovação de Lei Federal para ser criado. Dessa forma, as conquistas representadas pela legislação de regulamentação da profissão não são completamente vivenciadas pela categoria em razão dos entraves burocráticos à criação dos Conselhos de Secretariado.

\title{
4 METODOLOGIA
}

Pela revisão bibliográfica de abordagem qualitativa, o presente artigo pretendeu refletir e 
analisar a respeito da história do Secretariado Executivo no Brasil, em especial, das etapas pelas quais a profissão passou ao buscar o status de profissão consolidada.

Utilizando como fonte artigos científicos, consultas ao site da Federação Nacional de Secretárias e Secretários, a periódicos eletrônicos sobre Direito Trabalhista e Tributário e ao texto de Leis e Projetos de Leis relacionados à profissão secretarial, foi possível estabelecer comparações entre as etapas de consolidação consideradas típicas pela sociologia das profissões e as etapas já vivenciadas pela profissão do Secretariado no Brasil.

\section{ANÁLISE DOS RESULTADOS}

Pela comparação entre a história do Secretariado e as etapas de consolidação de uma profissão na lógica do profissionalismo, verifica-se que tais etapas se fizeram presentes na história dessa profissão.

As mudanças no perfil do profissional de secretariado ao longo dos anos, em que a simples execução de técnicas secretariais abriu espaço para uma figura polivalente, que se especializa nas competências necessárias a uma assessoria eficiente, indicam a tendência à especialização do conhecimento para a atuação na área.

A profissão tem se caracterizado por formação baseada mais em conceitos e teorias abstratas do que em longos treinamentos práticos. O tipo de atividade do secretário é de grande variedade de contingências e sua atuação depende do discernimento para adaptar conhecimentos e habilidades a cada circunstância. Assim o secretariado se classifica como uma especialização criteriosa teoricamente fundamentada, denominação utilizada por Freidson (1996) para profissões que possuem a marca de especialização característica do profissionalismo.

Outra marca do profissionalismo é o credenciamento em Ensino Superior. Observa-se a criação de cursos de formação em Secretariado de Nível Superior desde a década de 1960. Ainda que a legislação regulamentadora da profissão mantenha espaço para a formação em nível técnico, torna-a diferenciada em nomenclatura e atribuições da formação em nível superior.

Ademais, a atuação das Entidades de Secretários em favor da promulgação de Diretrizes para os cursos superiores de formação em Secretariado denota a importância que o diploma superior representa para o status profissional. Nesse sentido, a preocupação, as discussões e os eventos 
nacionais em apoio à produção de conhecimento científico em secretariado atestam não só o valor do credenciamento em nível superior, mas também da especialização do conhecimento.

Caberia afirmar que um grande número de pesquisas acadêmicas tem abordado temas relativos à importância do profissional de secretariado para as organizações, sua influência e seu poder no ambiente corporativo. Tal comportamento valida a observação de Freidson (1996) a respeito das profissões com formação em nível superior encontrarem na produção de seu corpo acadêmico base teórica a favor do status de sua profissão dentro do mercado de trabalho.

A característica do profissionalismo da autonomia profissional para realizar diagnósticos e controlar o mercado esbarra no caráter fortemente intervencionista da legislação e política brasileira sobre as profissões.

Para o secretariado, a luta pela consolidação e reconhecimento da profissão que dependiam da aprovação de legislações ou de permissão oficial para se efetivarem, só foi realizada pela arregimentação dos profissionais em entidades representativas organizadas.

Ainda que Freidson (1996) tenha considerado prescindível a atuação das Associações Profissionais para existência do profissionalismo, na história das conquistas de secretários e secretárias fica comprovada a importância desse tipo de entidade para que uma profissão obtenha garantias no mercado brasileiro.

Foi por meio da organização de associações, que mais tarde deram lugar aos sindicatos, e da Associação Brasileira de Entidades de Secretárias, substituída pela Federação Nacional de Secretárias e Secretários, que a categoria ganhou força para ser ouvida no meio político do qual dependia para fazer valer mecanismos de controle do mercado de trabalho.

Celebradas como as grandes conquistas da profissão, a Lei de Reconhecimento, seguida da Lei de Regulamentação, tem exata função de reservar certo tipo de posto de trabalho aos profissionais credenciados como secretários e de reservar a certo tipo de indivíduos a credencial da profissão.

Segundo Freidson (1996), as vantagens que a reserva de mercado representam para uma categoria profissional se contrapõem ao sentimento dos clientes dos serviços em sua percepção de que credenciamento não é garantia de trabalho adequado. Dessa forma, surgem mecanismos com a finalidade de criar confiança nos profissionais credenciados, como a adoção de um Código de Ética e a formação de um Conselho Profissional, que indicam uma maneira correta de exercer uma profissão e apuram desempenhos e desvios. O Código de Ética do Profissional do Secretariado é um documento com esse tipo de função, mas a impossibilidade de criação de um Conselho Profissional impede que sejam apurados desvios do comportamento ali recomendado.

Revista de Gestão e Secretariado - GeSec, São Paulo, v. 4, n. 2, p 01-24, jul./dez. 2013. 
Ao se examinar as cinco etapas que Harold Wilensky (1970, como citado em Marinho, 1986) considerou como características do processo de profissionalização típico, é possível identificar se a profissão de secretário as percorreu. Marinho (1986) analisou cinco profissões no mercado brasileiro, destacando marcas das cinco etapas de profissionalização pontuadas por Wilensky, quais sejam, as datas de criação dos primeiros Cursos de formação, da primeira Associação Profissional Nacional, da primeira regulamentação do exercício da profissão e da adoção do primeiro código de ética.

O secretariado, por ter sido incorporado como profissão do mundo empresarial, há muito tempo se caracteriza por uma ocupação de tempo integral. O ano de criação da primeira Associação Profissional em nível nacional é 1976 e o primeiro curso de graduação em Secretariado foi fundado em 1965. A profissão foi regulamentada pela Lei n. 7.377, de 30/09/1985, que foi complementada pela Lei n. 9.261, de 10/01/1996, mas anteriormente a Lei 6.556/78, de 5/9/1978, já estabelecia condições para o exercício da profissão. A adoção do Código de Ética Profissional ocorreu em 1983, sendo substituído por nova versão em 1989.

Assim, a profissão já teria percorrido as cinco etapas do profissionalismo típico, mas não teria alcançado total autonomia profissional porque, no Brasil, o controle profissional de pares depende da criação de Conselho Profissional aprovado por lei, como já foi mencionado.

\section{CONSIDERAÇÕES FINAIS}

As revisões bibliográficas dos conceitos relacionados ao profissionalismo e à história da profissão de Secretariado no Brasil puderam comprovar que a profissão, ao longo de anos de luta, conseguiu se estabelecer. Passou pelas etapas da profissionalização e foi capaz de criar os mecanismos necessários para a reserva de mercado e controle do credenciamento, ainda que isso tenha dependido muitas vezes da intervenção estatal.

Para conseguir impactar as ações do governo a favor da profissão, foi imprescindível que os profissionais se organizassem em entidades que os representasse. Essa necessidade de arregimentação comprova o conceito de profissionalismo que indica a proteção da profissão a partir do interesse e atuação dos próprios profissionais

Ações a favor de aspectos do profissionalismo, como apoio ao desenvolvimento de conhecimento científico em Secretariado e o fortalecimento dos cursos de formação em nível

Revista de Gestão e Secretariado - GeSec, São Paulo, v. 4, n. 2, p 01-24, jul./dez. 2013. 
superior, sempre serão necessárias por aumentarem o status da profissão no mercado de trabalho.

No entanto, os anseios da Federação Nacional de Secretárias e Secretários pela criação do Conselho Federal do Secretariado se justificam visto que a existência da instituição seria a única forma possível em nosso país de passar das mãos do Estado para as dos profissionais o controle sobre o credenciamento profissional e sobre a fiscalização dos profissionais credenciados.

\section{REFERÊNCIAS}

Bruno, I. M. (2006). O Poder de influência do profissional de secretariado no processo decisório das organizações. Dissertação de Mestrado, Pontifícia Universidade Católica de São Paulo, São Paulo, SP, Brasil. Recuperado em 17 junho, 2013, de <http://www.fenassec.com.br/pdf/artigos_trab_cientificos_xvconsec_1lugar_a. pdf >.

Castelo, M. J. (2007). A Formação acadêmica e a atuação profissional do Secretário Executivo. Monografia de Bacharelado em Secretariado Executivo, Universidade Estadual de Londrina, Londrina, PR, Brasil. Recuperado em 17 junho, 2013, de <http://www.fenassec.com.br/pdf/artigos_trab_cientificos_a_formacao_academica _e_a_atuacao_profissional_do_secretario_executivo_completa.pdf $>$.

Costa, B. S. da (2009). Prerrogativas processuais dos conselhos profissionais: natureza jurídica de direito público. Recuperado em 17 junho, 2013, de <http://dspace.idp.edu.br:8080/xmlui/bitstream/handle/123456789/271/Monografia_Bruno\%20S ampaio $\% 20 \mathrm{da} \% 20$ Costa.pdf? sequence $=1>$.

Decreto-lei n.. 5.452, de $1^{\circ}$. de maio de 1943 (1943). Aprova a consolidação das leis do trabalho. Recuperado em 15 junho, 2013, de http://www.planalto.gov.br/ccivil_03/decretolei/Del5452.htm.

Faria, S. M. \& Leão, I. B. (2007). Alguns aspectos da história da qualificação profissional no Brasil a partir de mil novecentos e noventa. Jornada do Grupo de Estudos e Pesquisas História, Sociedade e Educação no Brasil da Faculdade de Educação da Unicamp. Campo Grande, MS, Brasil (7). Recuperado em 9 maio, 2013, de <http://www.histedbr.fae.unicamp.br/acer_histedbr/jornada/jornada7/_GT2\%20PDF

/ALGUNS\%20ASPECTOS\%20DA\%20HIST\%D3RIA\%20DA\%20QUALIFICA\%C7\%C30\%2 OPROFISSIONAL\%20NO\%20\%20REPETIDO.pdf>.

Ferreira, F. D. (2011). A atuação do secretário executivo no setor público: o caso da Universidade Federal do Ceará. Dissertação de Mestrado, Universidade Federal do Ceará, Programa de Pósgraduação em Políticas Públicas e Gestão da Educação Superior - Poleduc, Fortaleza, CE, Brasil. 
Freidson, E. (1996, junho). Para uma análise comparada das profissões: a institucionalização do discurso e do conhecimento formais. Revista Brasileira de Ciências Sociais. São Paulo: anpocs, n. 31, ano 11, jun. 1996. Recuperado em 9 maio, 2013, de <http://www.anpocs.org.br/portal/publicacoes/rbcs_00_31/rbcs31_08.htm>

Kober, C. M. (2003). Profissões e competências. XI Congresso Brasileiro de Sociologia. Unicamp, Campinas, SP, Brasil. Recuperado em 9 maio, 2013, de $<$ http://www.sbsociologia.com.br/portal/index.php?option=com_docman\&task=doc_download\& gid=1565\&Itemid=171>.

Krein, J. D. (2007). Tendências Recentes nas relações de emprego no Brasil: 1990-2005. Tese de Doutorado, Universidade Estadual de Campinas, Campinas, SP, Brasil. Recuperado em 9 maio, 2013, de <http://www.bibliotecadigital.unicamp.br/document/?down=vtls000430974>.

Marinho, M. J. M. C. (1986). Profissionalização e credenciamento: a política das profissões. Rio de Janeiro: Senai.

Mensagem de Veto n. 663, de 9 de maio de 2000 (2000). Presidência da República, Casa Civil, Subchefia para Assuntos Jurídicos. Recuperado em 18 junho, 2013 de <http://www.planalto.gov.br/ccivil_03/VETO_TOTAL/Mv663-00.htm>.

Nascimento, L. C. (2007, janeiro/junho). Profissionalismo: expertise e monopólio no mercado de trabalho. Revista Perspectivas Contemporâneas, vol. 2, n. 1, Campo Mourão, PR, Brasil. Recuperado em $10 \quad$ março, $2013, \quad$ de <http://revista.grupointegrado.br/revista/index.php/perspectivascontemporaneas/article/viewFile/ $\underline{383 / 180}>$.

Natalense, M. L. C. (1998). A secretária do futuro. Rio de Janeiro: Qualitymark.

Sála, J. S. (2008). Guia de fontes de informação para secretários executivos. Brasília, DF, Brasil. $\begin{array}{lllll}\text { Recuperado em } & 13 & \text { dezembro, }\end{array}$ <http://www.fenassec.com.br/pdf/artigos_trabalhos_guia_secretariado_janeide.pdf $>$.

Silva, J. A. da (2005). Direito Constitucional Positivo. (24a ed.) São Paulo: Malheiros.

Soares, S.; Servo, L. M. S. \& Arbache, J. S., (2001). O que (não) sabemos sobre a relação entre abertura comercial e mercado de trabalho no Brasil. Anais do Encontro Nacional de Economia, ANPEC - Associação Nacional dos Centros de Pós-graduação em Economia. Salvador, BA, Brasil (29). Recuperado em 9 maio, 2013 de <http://www.anpec.org.br/encontro2001/artigos/200103412.pdf $>$.

Sousa Neto, M. F. de (2005, maio/agosto). O ofício, a oficina e a profissão: reflexões sobre o lugar social do professor. Cad. Cedes, Campinas, vol. 25, n. 66, pp. 249-259. Recuperado em 9 maio, 2013, de 〈http://www.scielo.br/pdf/ccedes/v25n66/a07v2566.pdf>. 
Velloso, A. P. (2012, julho). Contribuições (anuidades) devidas aos Conselhos de Fiscalização Profissional: inconstitucionalidade da Lei 12.514/2011. Jornal Carta Forense. Recuperado em 18 junho, 2013 de <http://www.cartaforense.com.br/conteudo/colunas/contribuicoes-anuidadesdevidas-aos-conselhos-de-fiscalizacao-profissional-inconstitucionalidade-da-lei$\underline{125142011 / 8841>}$. 